\title{
Open Researcher and Contributor ID (ORCID): vital for surgical endoscopy
}

\author{
Mark A. Talamini ${ }^{1} \cdot$ George B. Hanna $^{2}$
}

Received: 1 August 2017/Accepted: 2 August 2017/Published online: 15 August 2017

(C) Springer Science+Business Media, LLC 2017

The world of publishing is changing at an accelerating pace, and scientific publishing is changing just as fast. Our channel of dissemination, surgical endoscopy, continues to adapt to the rapidly changing environment.

Electronic submission of manuscripts has promoted an exponential expansion of submissions and authors, and turned the world of surgery into a digital village. And this has created a problem that most authors and many readers have experienced. Who is who? This is particularly a problem if you have a common name, such as Jones, Lee (Li, Le, etc.) or Sanchez. But even for Mark Talamini, I can also be Mark A Talamini, Mark A. Talamini, and Mark Adams Talamini, each with a distinct digital signature. Worse, no one carries only one email in the current digital environment. I have had more than ten in the last decade. So imagine the difficulty of clearly identifying who is who in a manuscript with 4 coauthors to ensure that all of the releases and documentation are in order before processing a manuscript. On the citation end, I have manuscripts in which I am differentially identified by all of my aforementioned names, often in different places.

Enter Open Researcher and Contributor ID (ORCID) as the universal solution to this, and a number of other dilemmas. ORCID provides a single 16-digit numeric identifier for authors that will unify any and all previous identities once and for all. The numbers are stored in a central registry. During registration, all names and email addresses can be entered to enable unification of your digital identifiers. The process to simply register is quick and painless, and can be carried out at orcid.org. Additional information can be added regarding your research and academic world, if you desire. Your current published manuscripts can be imported to your ORCID account via SCOPUS, Researcher ID and/or CrossRef Metadata Search.

Security online is, of course, always a concern. ORCID has been constructed to maintain and address security. Default privacy settings are easily controlled, as well as custom levels for each item. The account can be set up so that only the account holder has access. This level of privacy, of course, eliminates the option of linking to CVmaintaining sites such as SCOPUS.

We, as the editors-in-chief of surgical endoscopy, urge all of our submitting authors and coauthors to obtain an ORCID identifier. It will save you headaches and make the flow of manuscript review smoother and faster. Post publication, it will make collation and identification of your work simple.

Mark A. Talamini

mark.talamini@stonybrookmedicine.edu

1 Department of Surgery, Stony Brook Medicine, Stony Brook, NY, USA

2 Division of Surgery, Imperial College London, London, UK 